\title{
Specificity of Escherichia coli Heat-Labile Enterotoxin Investigated by Single-Site Mutagenesis and Crystallography
}

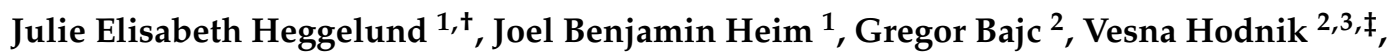 \\ Gregor Anderluh ${ }^{3}(\mathbb{D}$ and Ute Krengel $1, * \mathbb{C}$ \\ 1 Department of Chemistry, University of Oslo, Postbox 1033 Blindern, 0315 Oslo, Norway; \\ j.e.heggelund@farmasi.uio.no (J.E.H.); j.b.heim@kjemi.uio.no (J.B.H.) \\ 2 Department of Biology, Biotechnical Faculty, University of Ljubljana, Jamnikarjeva 101, 1000 Ljubljana, \\ Slovenia; gregor.bajc@bf.uni-lj.si (G.B.); vesna.hodnik@novartis.com (V.H.) \\ 3 Department of Molecular Biology and Nanobiotechnology, National Institute of Chemistry, Hajdrihova 19, \\ 1000 Ljubljana; Slovenia; gregor.anderluh@ki.si \\ * Correspondence: ute.krengel@kjemi.uio.no; Tel.: +47-2285-5461 \\ + Current address: Department of Pharmacy, University of Oslo, Postbox 1068 Blindern, 0316 Oslo, Norway. \\ $\ddagger$ Current address: Lek d.d., Kolodvorska 27, 1234 Mengeš, Slovenia.
}

Received: 28 January 2019; Accepted: 31 January 2019; Published: 6 February 2019

\begin{abstract}
Diarrhea caused by enterotoxigenic Escherichia coli (ETEC) is one of the leading causes of mortality in children under five years of age and is a great burden on developing countries. The major virulence factor of the bacterium is the heat-labile enterotoxin (LT), a close homologue of the cholera toxin. The toxins bind to carbohydrate receptors in the gastrointestinal tract, leading to toxin uptake and, ultimately, to severe diarrhea. Previously, LT from human- and porcine-infecting ETEC (hLT and pLT, respectively) were shown to have different carbohydrate-binding specificities, in particular with respect to $\mathrm{N}$-acetyllactosamine-terminating glycosphingolipids. Here, we probed 11 single-residue variants of the heat-labile enterotoxin with surface plasmon resonance spectroscopy and compared the data to the parent toxins. In addition we present a $1.45 \AA$ crystal structure of pLTB in complex with branched lacto- $N$-neohexaose (Gal $\beta 4 \mathrm{GlcNAc} \beta 6[\mathrm{Gal} \beta 4 \mathrm{GlcNAc} \beta 3] \mathrm{Gal} \beta 4 \mathrm{Glc})$. The largest difference in binding specificity is caused by mutation of residue 94 , which links the primary and secondary binding sites of the toxins. Residue 95 (and to a smaller extent also residues 7 and 18) also contribute, whereas residue 4 shows no effect on monovalent binding of the ligand and may rather be important for multivalent binding and avidity.
\end{abstract}

Keywords: bacterial toxin; cholera toxin; Escherichia coli heat-labile enterotoxin; lectin; $\mathrm{N}$-acetyllactosamine binding; neutral glycosphingolipids; protein-carbohydrate interactions; surface plasmon resonance spectroscopy; X-ray crystal structure

\section{Introduction}

The heat-labile enterotoxin (LT), a homologue of the cholera toxin (CT), is produced by enterotoxigenic Escherichia coli (ETEC). ETEC is responsible for millions of diarrheal cases and more than 50,000 deaths every year [1]. The mortality of the disease is declining, but the morbidity is not, despite improvements in sanitation facilities. ETEC infection in children often leads to long-term health problems like stunted growth and reduced cognitive abilities, triggering a vicious cycle of poverty [2]. The disease also affects travellers to endemic areas, including medical and military personnel, and has further been linked to chronic diseases like irritable bowel syndrome [3]. The infection spreads through the fecal-oral route, aggravated by the watery diarrhea caused by the enterotoxin. 
$\mathrm{LT}$ and $\mathrm{CT}$ belong to the $\mathrm{AB}_{5}$ toxin family, consisting of one A-subunit and five B-subunits $[4,5]$. The A-subunit is catalytically active and is anchored to the center of the torus-shaped B-pentamer, which is responsible for the binding to epithelial cells. The B-pentamers of LT (LTB) and CT (CTB) share the same fold, and have approximately $80 \%$ sequence identity [5]. The binding to their main cellular receptor, the monosialoganglioside GM1, is one of the strongest carbohydrate-protein interactions known, with a binding constant of $43 \mathrm{nM}[6,7]$. The binding is enhanced by at least an order of magnitude when all five binding sites are occupied [8].

There are several crystal structures of CTB and LTB in complex with the GM1 pentasaccharide Gal $\beta 3$ GalNAc $\beta 4[N e u A c \alpha 3]$ Gal $\beta 4 G l c$ (Protein Data Bank (PDB) ID: 3CHB [9], 2XRQ [10], 1CT1 [11]). GM1 binds at the base of the B-pentamer, which faces the membrane, anchored by its two terminal residues: galactose and sialic acid (NeuAc). The galactose residue is buried in a deep cavity, whereas sialic acid binds mainly through water-mediated interactions at the protein surface.

Both LT and CT also bind other glycoconjugates at the cell surface, however, LT is generally more promiscuous and binds to a wider variety of glycosphingolipids than $\mathrm{CT}$, including disialoganglioside GD2, asialo-GM1 and lacto- $N$-neotetraosylceramide (LNnT-Cer; paragloboside) $[12,13]$ as well as intestinal polyglycosylceramides and sialic-acid containing glycosphingolipids [14]. Common for most of the additional purified ligands is that they contain a terminal galactose connected to either GalNAc or GlcNAc (Gal $\beta 3$ GalNAc $\beta 4$ or Gal $\beta 4 G l c N A c \beta 3$ ). There are two natural variants of LT, one isolated from human-infecting ETEC (hLT) and one from porcine-infecting ETEC (pLT). Although these two are very similar, they have different binding affinities. The B-pentamers hLTB and PLTB are identical except for four residues: 4,13,46, and 102, and of these, only residue 13 is situated at the primary binding site. Residue 13 is a histidine in most hLTB strains and an arginine in pLTB. A CT-like toxin from the bacterium Citrobacter freundii has also been shown to bind to LNnT-Cer, with an even higher affinity than PLTB [15]. This toxin has approximately 75\% sequence identity to hLTB and CTB, and slightly lower sequence identity to pLTB.

In previous work, Teneberg and co-workers investigated the binding specificities of pLTB, hLTB, and CTB to two $N$-acetyllactosamine-terminated glycosphingolipids, branched lacto- $N$-neohexaosylceramide (LNnH-Cer, Gal $\beta 4$ GlcNAc $\beta 6[G a l \beta 4 G l c N A c \beta 3] G a l \beta 4 G l c \beta C e r)$ and linear lacto- $N$-neohexaosylceramide (Gal $\beta 4 \mathrm{GlcNAc} \beta 3 \mathrm{Gal} \beta 4 \mathrm{GlcNAc} \beta 3 \mathrm{Gal} \beta 4 \mathrm{Glc} \beta \mathrm{Cer}$ ), immobilized to microtiter wells [16]. pLTB was shown to bind the strongest to both ligands, hLTB weaker, and CTB hardly at all. To test if the difference between hLTB and PLTB was due to residue 13, we subsequently generated the protein variant hLTB H13R, which showed enhanced binding to branched LNnH-Cer, strongly indicating that residue 13 is the key residue for this interaction [10]. However, the crystal structure of pLTB in complex with lacto- $N$-neotetraose (LNnT, Gal $\beta 4 G$ GlcNAc $\beta 3$ Gal $\beta 4 G$ Glc; PDB ID: 2XRS [10]), shows no clear interaction between Arg13 and the ligand, suggesting that other residues are also important.

The differences between CTB and LTB were also investigated by cassette mutagenesis more than 20 years ago. Mutating residues 1-25 in concert with 94-95 in CTB gave rise to a toxin with binding specificities indistinguishable from hLTB, named LCTBH [14]. Changing residue Ser4 back to CTB-specific Asn4 generated toxin variant LCTBK, which showed strongly reduced binding to LNnT-Cer and LNnH-Cer [17], suggesting that residue 4 could be the key factor within the first block. Residue 4 lies at a second binding site, at the lateral side of the toxin, approximately $10 \AA$ away from the primary binding site $[18,19]$. This patch was recently shown to bind blood group antigens and derivatives from human milk with millimolar affinities, involving residues 3, 4, 7, 18, 46, 47, and 94 [18-23]. Cross-talk between the two binding sites has been hypothesized earlier [10,24-26], and may be mediated through hydrogen-bonding networks connecting the two sites, and through the $\mathrm{N}$-terminal $\alpha$-helix. Recent NMR studies of hLTB identified residues with chemical shift changes upon titration with LNnT, supporting this hypothesis [27]. The largest chemical shift perturbations were seen for the backbones of Gln61 and the 50s loop, Gly33 and Asn14 (in order of the magnitude of the change; His13 could not be assigned), all located near the primary binding site. In addition, smaller 
chemical shift changes were observed for residues located between the two binding sites: 16, 38, 30, 96, and 8 (in order of the magnitude of the change), strongly suggesting cross-talk between the sites.

In order to test which residues are important for the binding of $\mathrm{N}$-acetyllactosamine-terminated ligands to the primary binding site, we generated 10 single-site variants of pLTB towards residues of CTB or hLTB (Figure 1), and probed these for binding to the tetrasaccharide LNnT. In addition, we generated the hLTB variant H13R. A similar construct was previously tested for binding of the branched $\mathrm{N}$-acetyllactosamine-terminated glycosphingolipid LNnH-Cer, in microtiter well assays [10]. Here, we probed the binding of both pLTB R13H and hLTB H13R for binding to linear LNnT, and the binding of pLTB R13H to branched $\mathrm{LNnH}$, using surface plasmon resonance (SPR) spectroscopy. We further solved the crystal structure of wild-type (wt) pLTB in complex with LNnH to $1.45 \AA$ resolution and compared it to the pLTB-LNnT structure (PDB ID: 2XRS [10]), revealing a comprehensive picture of the molecular interactions.

a

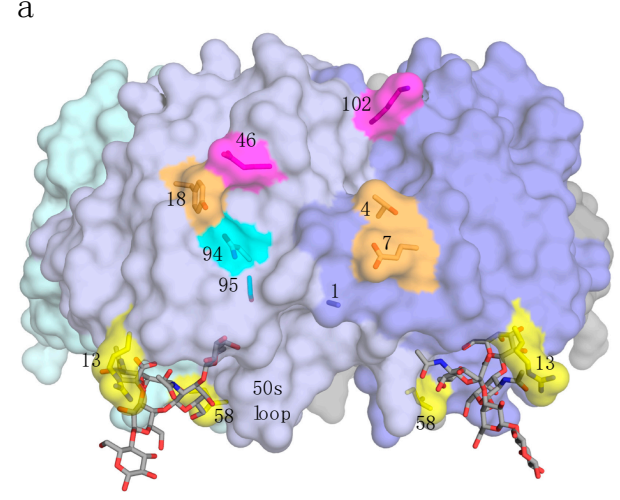

$\mathrm{b}$

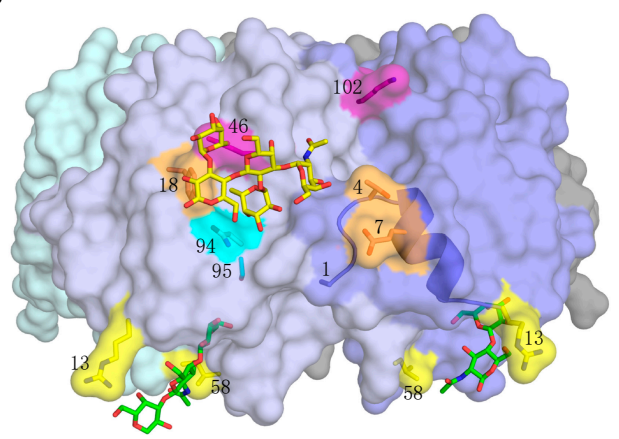

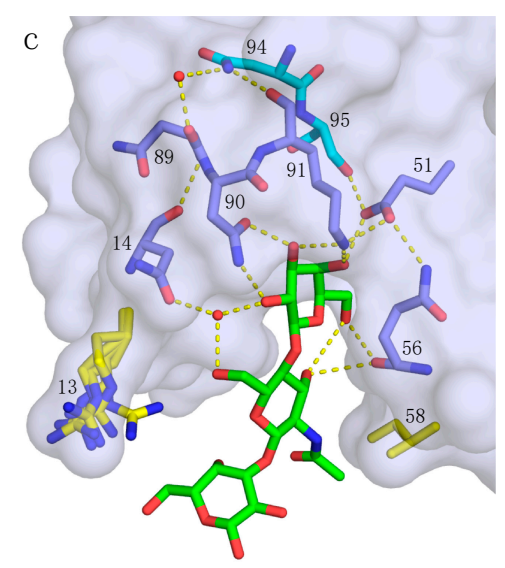

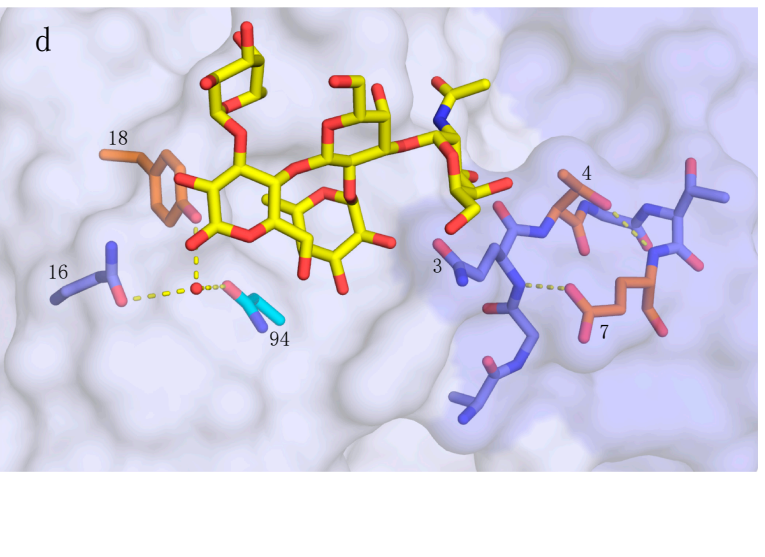

Figure 1. pLTB structure and interactions. Residues and features of special importance for this work are marked, with residues colored in groups, as discussed in Section 2. (a) pLTB (PDB ID: 2XRQ [10]) shown in surface representation, colored by subunit. The GM1 oligosaccharide is shown in stick representation, with grey carbons. (b) pLTB in complex with lacto- $N$-neotetraose (LNnT; PDB ID: 2XRS [10]), in a collage with an analogue of the blood group A-pentasaccharide bound to the secondary binding site, superimposed from hLTB structure 2O2L [19]. Not all of the carbohydrate residues were modeled for LNnT, due to weak electron density at the non-reducing end. The $\alpha$-helix connecting residues 1 through 14 is shown in cartoon representation. (c) Close-up view of the primary binding site of pLTB with LNnT (PDB ID: 2XRS [10]). Important residues are shown in stick representation, and the hydrogen-bonding network in yellow dotted lines, extending up to residue 94 (cyan). Two conserved water molecules are depicted as red spheres. Residue 13 (yellow) adopts alternative conformations in the different subunits, and residue 58 (yellow) has van der Waals contacts to the methyl group of GlcNAc. (d) Close-up view of relevant residues at the secondary binding site of pLTB (PDB ID: 2XRS [10]), with the A-pentasaccharide (from PDB ID: 2O2L [19]) superimposed in yellow sticks. Important residues on both sides of the secondary binding site are shown. 


\section{Results}

\subsection{Quality Control}

In order to verify proper folding of the toxin variants, we subjected all proteins to circular dichroism (CD) spectroscopy (Figure S1). In addition, several protein variants were tested for binding to the GM1 pentasaccharide to confirm that the primary binding site was intact, even when binding to LNnT was compromised. Wild-type pLTB and variant T4N bound with similar affinity to the GM1 pentasaccharide as previously reported, pLTB variant N94H bound more strongly, whereas S95A had a slightly lower affinity, but still in the nanomolar range (Table 1). The most notable change in GM1 binding affinity was observed for pLTB variant I58A, which dropped two orders of magnitude compared to wt pLTB, to micromolar affinity.

Table 1. $K_{\mathrm{D}}$ values measured by SPR, grouped by analyte and batch number

\begin{tabular}{|c|c|c|c|c|c|c|}
\hline $\begin{array}{l}\text { Protein } \\
\text { Variant }\end{array}$ & GM1a & LNnT Batch 1 & LNnT Batch 2 & LNnT Batch 3 & LNnT Batch 4 & LNnH \\
\hline pLTB wt & $37 \pm 0.5 \mathrm{nM}$ & $6.7 \pm 0.5 \mathrm{mM}$ & - & $9.4 \pm 0.1 \mathrm{mM}$ & $8.0 \pm 0.6 \mathrm{mM}$ & $5 \pm 1 \mathrm{mM}$ \\
\hline pLTB T4N & $32 \pm 0.3 \mathrm{nM}$ & - & - & $8.6 \pm 0.1 \mathrm{mM}$ & $7.8 \pm 0.7 \mathrm{mM}$ & - \\
\hline pLTB T4S & - & - & - & $8.9 \pm 0.4 \mathrm{mM}$ & - & - \\
\hline pLTB E7D & - & - & $12 \pm 3 \mathrm{mM}^{*}$ & - & - & - \\
\hline pLTB R13H & - & $9.3 \pm 1.7 \mathrm{mM}$ & - & - & - & $7 \pm 1 \mathrm{mM}$ \\
\hline hLTB H13R & - & $11.5 \pm 0.2 \mathrm{mM}$ & - & - & - & - \\
\hline pLTB Y18H & - & - & - & $10.7 \pm 0.1 \mathrm{mM}$ & - & - \\
\hline pLTB E46A & - & - & - & $9.8 \pm 0.1 \mathrm{mM}$ & - & - \\
\hline pLTB I58A & $2.3 \pm 1.7 \mu \mathrm{M}$ & - & n.b. & - & - & - \\
\hline pLTB N94H & $23 \pm 1 \mathrm{nM}$ & - & $>40 \mathrm{mM}^{* *}$ & - & - & - \\
\hline pLTB S95A & $65 \pm 4 \mathrm{nM}$ & - & - & $18 \pm 1.4 \mathrm{mM}$ & - & - \\
\hline pLTB K102E & $34 \pm 0.8 \mathrm{nM}$ & - & - & $9.7 \pm 0.5 \mathrm{mM}$ & - & - \\
\hline hLTB wt & - & - & - & $16 \pm 0.03 \mathrm{mM}$ & - & - \\
\hline СТВ & - & - & - & $>36 \mathrm{mM}^{* *}$ & - & - \\
\hline
\end{tabular}

${ }^{*}$ For variant E7D, four titrations were carried out, giving $K_{\mathrm{D}}$ values of $>27 \mathrm{mM}, 11.5 \mathrm{mM}, 9.8 \mathrm{mM}$, and $15.3 \mathrm{mM}$. The reported $K_{\mathrm{D}}$ does not include the outlier. ${ }^{* *}$ Accurate value impossible to determine since they are outside of the concentration range of $\mathrm{LNnT}$ analyte $(30 / 40 \mathrm{mM})$ used in this study.

\subsection{Surface Plasmon Resonance Spectroscopy with Lacto-N-Neotetraose}

To date, most of the binding studies with $N$-acetyllactosamine-terminated ligands were carried out with microtiter well binding assays, revealing differences in multivalent binding, or avidity. In this work, we applied surface plasmon resonance (SPR) spectroscopy, in order to detect differences in monovalent binding. Each protein was immobilized on a sensor chip, and the binding to the soluble tetrasaccharide LNnT was measured. LNnT was purchased four times, here referred to as batches 1 to 4 . In agreement with previous experiments using glycosphingolipids, LNnT has slightly higher affinity for pLTB than for hLTB, and poor affinity for CTB (Table 1; selected sensorgrams are shown in Figure 2).

In the following paragraphs, we describe the results for the different toxin variants (Tables 1 and 2), starting from the membrane-facing primary binding site, via residues connecting the primary and secondary toxin binding sites, to the secondary binding site, for blood group antigens. The final substitution discussed (residue 102) is at the B-subunit interface at the top of the B-pentamer (Figure 1a), where the A-subunit is positioned. 


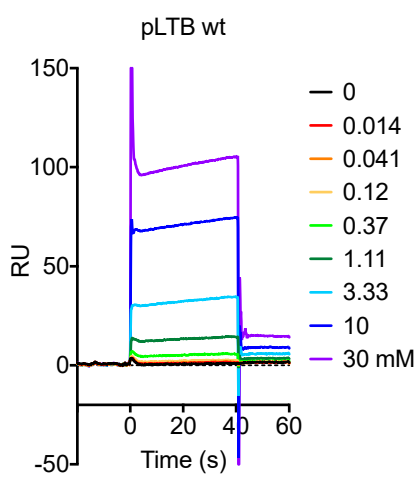

hLTB wt

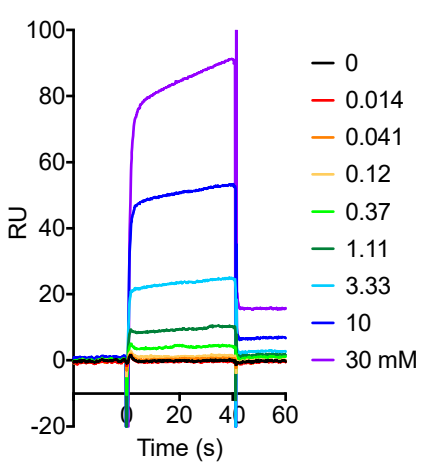

El Tor CTB

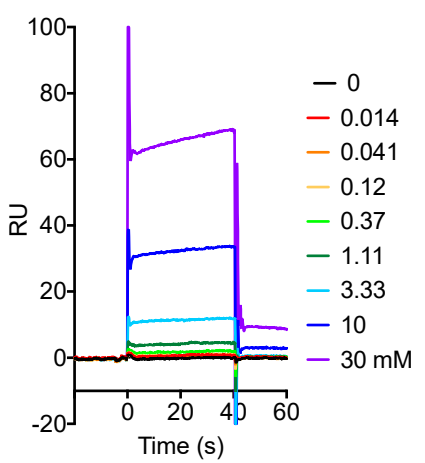

pLTB wt

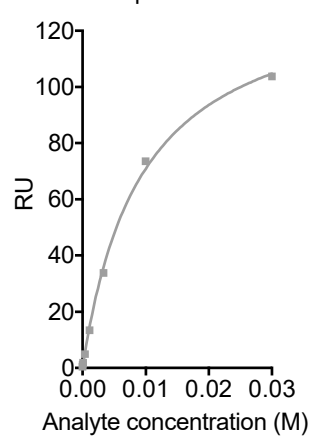

hLTB wt

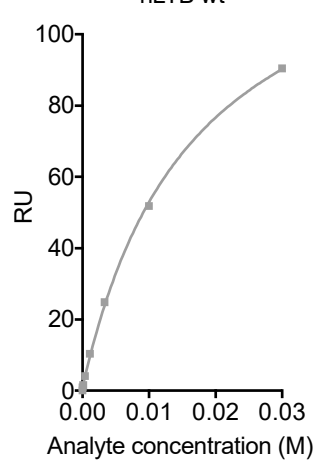

El Tor CTB

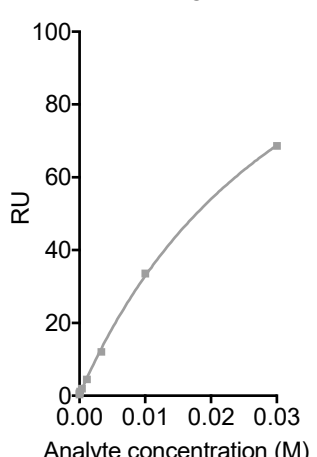

pLTB T4N

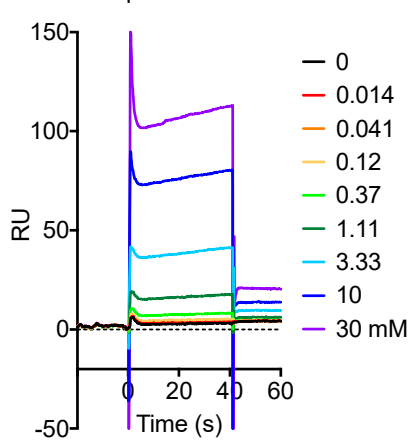

pLTB N94H

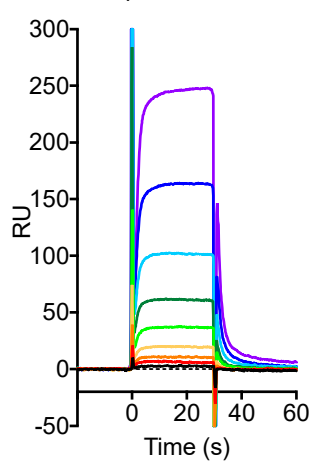

pLTB S95A

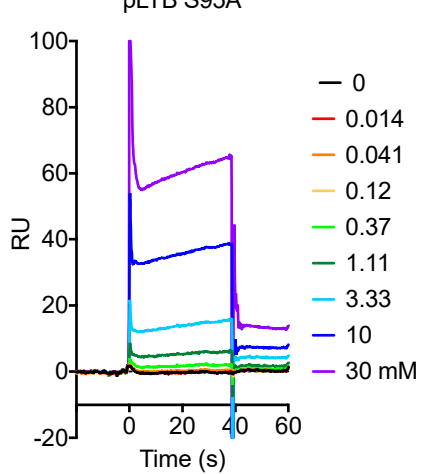

$$
\begin{aligned}
& -0.16 \\
& -0.31 \\
& -0.63 \\
& -1.25 \\
& -2.5 \\
& -5 \\
& -10 \\
& -20 \\
& -40 \mathrm{mM} \\
&
\end{aligned}
$$

pLTB T4N

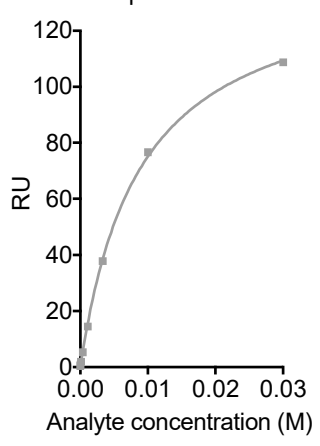

pLTB N94H
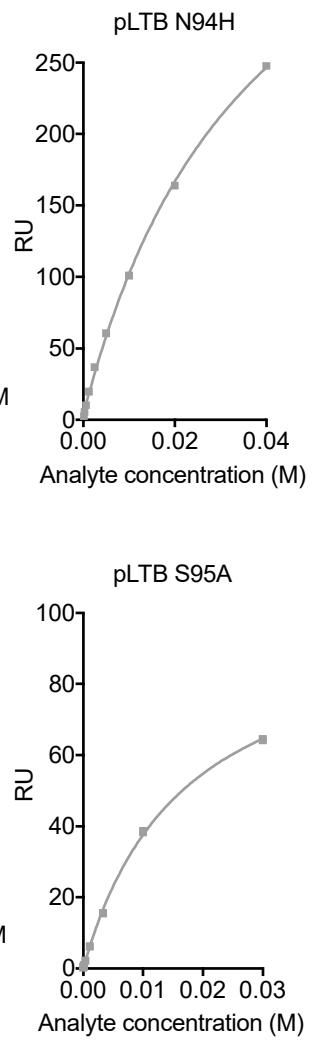

Figure 2. Selected SPR sensorgrams and affinity plots for analyte LNnT. The colored graphs are responses to increasing concentrations of the analyte $\mathrm{LNnT}$, in multi-steady state affinity experiments (response units (RU) versus analyte concentration). The resulting steady-state values are plotted as dots with a fitted curve, using the Biacore T100 evaluation software. The responses are dependent on the protein immobilization rates, therefore the RU-axes are not comparable between protein variants. 
Table 2. Sequence and affinity differences between PLTB, hLTB, CTB, and toxin variants.

\begin{tabular}{cccccc}
\hline Residue & pLTB & hLTB & CTB * & Toxin Variant & Effect on LNnT Affinity \\
\hline 1 & Ala & Ala & Thr* & & \\
$4^{* *}$ & Thr & Ser & Asn & pLTB T4N/T4S & Like pLTB wt \\
7 & Glu & Glu & Asp & pLTB E7D & Lower affinity \\
10 & Ser & Ser & Ala & - & - \\
13 & Arg & His & His & pLTB R13H & Similar to pLTB wt \\
& & & & hLTB H13R & Similar to hLTB wt \\
18 & Tyr & Tyr & Tyr & pLTB Y18H & Slightly lower affinity \\
20 & Ile & Ile & Leu* & - & - \\
25 & Leu & Leu & Phe & - & - \\
31 & Met & Met & Leu & - & - \\
38 & Val & Val & Ala & - & - \\
44 & Ser & Ser & Asn & - & - \\
46 & Glu & Ala & Ala & pLTB E46A & Like pLTB wt \\
47 & Thr & Thr & Ile * & - & - \\
58 & Ile & Ile & Ile & pLTB I58A & No binding \\
75 & Thr & Thr & Ala & - & - \\
80 & Thr & Thr & Ala & - & - \\
82 & Ile & Ile & Val & - & - \\
83 & Asp & Asp & Glu & - & - \\
94 & Asn & Asn & His & pLTB N94H & Lower affinity \\
95 & Ser & Ser & Ala & pLTB S95A & Lower affinity \\
102 & Lys & Glu & Ala & pLTB K102E & Like pLTB wt \\
\hline
\end{tabular}

* There are two major V. cholerae biotypes, classical, and El Tor. Here, we studied the El Tor variant, which differs from classical CTB in residues 18 (H18Y) and 47 (T47I). Compared to recombinant CTB used in previous studies, also residues 1 (A1T) and 20 (I20L) differ [14,17]. Since pLTB substitution A1T was discussed in previous work [10], we also performed preliminary experiments for this variant, which showed a similar affinity compared to wt pLTB, and thus seems to be of minor importance for LNnT binding. ${ }^{* *}$ Color coding of residues according to Figure $1 \mathrm{a}, \mathrm{b}$ and Sections 2.2.1-2.2.4. (yellow, primary binding site, discussed in Section 2.2.1; cyan, between primary and secondary binding site, Section 2.2.2; orange, secondary binding site, Section 2.2.3; magenta, residues discussed in Section 2.2.4).

\subsubsection{Primary Binding Site Residues 13 and 58}

The only residues differing between PLTB and hLTB are at positions 4, 13, 46, and 102 (Table 2). Of these, residue 13 is the only residue situated in the primary binding site. It was previously suggested that Arg13 is the main cause for the difference in binding patterns [16,28], a hypothesis subsequently supported by experimental findings that the hLTB variant H13R bound as strongly as pLTB to branched LNnH-Cer in microtiter well assays [10]. However, when we tested the variants pLTB R13H and hLTB H13R, we measured only a small difference in affinity to the linear tetrasaccharide LNnT by SPR spectroscopy compared to the wild-type proteins (Table 1). This fits with the observation that there are no physical interactions between residue 13 and the ligand in the crystal structure of pLTB in complex with LNnT (PDB ID: 2XRS [10]). Together, this suggests that residue 13 does not significantly affect the binding to soluble, linear $\mathrm{N}$-acetyllactosamine-terminated structures.

Residue 58 is a primary-site residue located in the flexible 50s loop at the base of the toxin (Figure 1) that is identical in all three toxins. This residue was predicted to be important for the binding of LNnT by interactions between the Ile58 side chain and the $N$-acetyl group of GlcNAc [10]. To verify that LNnT only binds to the primary site in PLTB, and not to the secondary binding site, we mutated Ile58 to Ala, which has a shorter side chain. The I58A mutation abolished the binding to LNnT (Tables 1 and 2), strengthening this hypothesis. This substitution also strongly affected binding to GM1, as discussed in Section 2.1. These results further suggest the importance of an entropic effect for ligand binding to the primary site, as predicted [10], with largest implications for weak binders like $\mathrm{N}$-acetyllactosamine-terminating glycosphingolipids. 


\subsubsection{Residues 94 and 95}

Residues 94 and 95 are located between the two binding sites, with residue 95 positioned closer to the primary binding site than residue 94 (Figure 1). In LTB, the side chain of Ser95 engages in a hydrogen bond to Glu51 (PDB ID: 2XRS and 2XRQ [10]), an interaction that cannot be formed by CTB-specific Ala95 due to its missing hydroxyl group. Glu51 directly interacts with the terminal galactose of LNnT (Figure 1c), and further forms H-bonds to Gln56 and Lys91, which also binds the terminal galactose. In addition, Ser95 engages in a water-mediated bond to the backbone of Ile96 (not shown). Together, these features contribute to stability at the primary binding site. The side chain of residue 94 stretches into the secondary binding site, where it is involved in a water-mediated binding network also including the side chains of residues 16 and 18 [18,19] (Figure 1d) as well as Asn89, which via Asn14 and Asn90 links back to the primary binding site (Figure 1c). Residues 94 and 95 have previously only been mutated in combination, with LTB-specific residues (Asn94 and Ser95) correlating with stronger binding to $\mathrm{N}$-acetyllactosamine-terminated glycosphingolipids compared to CTB residues (His94 and Ala95) [14]. In the SPR experiments presented here, both residues were proven to have an effect on the binding affinity, with $\mathrm{N} 94 \mathrm{H}$ showing the stronger effect (Tables 1 and 2).

\subsubsection{Secondary Binding Site Residues 4, 7, and 18}

Intriguingly, binding to $\mathrm{N}$-acetyllactosamine-terminated structures was found to be synergistically enhanced when LTB-specific residues Asn94 and Ser95 were introduced together with hLTB residues $1-25$ in an LTB/CTB chimera called LCTBH $[14,17]$. This sequence contains important determinants of the secondary toxin binding site, which have already been in the focus of previous studies $[10,17,18,20,27]$. In particular, residue 4 was attributed major significance since back-substitution of LTB-specific Ser4 to CTB-specific Asn4 (creating toxin variant LCTBK) resulted in a complete loss of the chimera's favourable binding properties [17].

In the crystal structures of the three toxins, residues 4 and 7 are some of the few amino acids that show side chain deviations, leading to differences in H-bonding patterns. They are positioned at two sides of a hairpin loop at the lateral side of the toxin, in the secondary binding site (Figure 1d). An $\alpha$-helix stretches from residues 4 and 7 to residues 13 and 14, linking the secondary to the primary binding site (Figure 1b). In contrast to previous data, we could not observe any significant change in affinity upon substituting pLTB-specific Thr4 to either hLTB-specific residue Ser4 or CTB-specific Asn4, whereas substitution of residue 7 (E7D) resulted in decreased binding affinity (Tables 1 and 2).

Tyr18 is positioned at the opposite side of the secondary binding site, H-bonding to residues 94 and 16, situated closer to the primary binding site (Figure 1d). His18 can maintain a similar, but not identical hydrogen-bonding pattern as Tyr18. We saw slightly weaker binding $\left(K_{\mathrm{D}}=10.7 \mathrm{mM}\right.$ versus $9.4 \mathrm{mM}$ ) for the His18 variant, however, the difference is small and at the border of the precision limits of the measurements (Table 1).

\subsection{4. pLTB-Specific Residues 46 and 102}

Residues 46 and 102 differ between hLTB and pLTB. Residue 46 is positioned at the top center of the secondary binding site, and residue 102 is located even further away from the primary binding site, close to the surface interacting with the A-subunit (Figure 1b). Neither the substitution of Glu46 to Ala (E46A) nor Lys102 to Glu (K102E) had any effect on the binding affinity to LNnT in our experiments (Tables 1 and 2). 


\subsection{Surface Plasmon Resonance Spectroscopy with Lacto-N-Neohexaose}

hLTB variant H13R was previously shown to enhance binding to branched LnNH-Cer to pLTB wild-type levels in microtiter well assays, strongly suggesting that residue 13 is the cause of the difference between the two toxins [10]. We therefore set out to test residue 13 variants (pLTB and hLTB) for differences in monovalent binding. However, we only found small differences in binding affinity that were statistically not significant compared to the variation we observed between analyte batches (Table 1). Moreover, due to the high costs of the analyte, we only performed few experiments. The differences observed are not sufficient to explain the previous results from microtiter well assays.

\subsection{Crystal Structures of $p L T B$ wt with Lacto-N-Neohexaose}

Given the inconclusive results from the SPR analysis presented in Section 2.3, we decided to determine the crystal structure of pLTB in complex with branched LNnH. The structure was obtained after co-crystallization and refined to a resolution of $1.45 \AA\left(R / R_{\text {free }}=17.5 / 20.1\right.$; Figure 3 , Table 3). The crystal contained two B-pentamers in the asymmetric unit, giving us access to 10 crystallographically distinct B-subunits. The B-pentamers are positioned "top-to-top", with the primary binding sites on opposite ends, similarly to recent LTB and CTB structures [20,26] (Figure 3a). The ligand $\mathrm{LNnH}$ is present in two of the 10 primary binding sites, on opposite ends of the decamer, and characterized by high-quality electron density (Figure 3a,b). Ligand binding stabilized the 50s loop (residues 51 to 60), which is disordered in all other subunits. LNnH binds with the $\beta 3$-branch in the galactose pocket, as predicted [16], and superimposes well with the $1.8 \AA$ crystal structure of pLTB in complex with LNnT (PDB ID: 2XRS [10]) (Figure 3d), whereas for GM1 (PDB ID: 2XRQ [10]), only the terminal Gal superimposes well with $N$-acetyllactosamine-terminated ligands (Figure 3e). The $\beta 6$-branch is folded back on the reducing end of the sugar, with the $\beta 6$-glycosidic bond interacting with Arg13 (Figure 3c; Table 4). The terminal galactose of the $\beta 6$-branch is exposed, explaining why substitution can occur at the 2-, 3-, or 4-position [28]. Both ligand binding sites are in close proximity to neighboring molecules in the crystal, with similar contacts in both cases, therefore we cannot exclude that the $\beta 6$-branch may adopt a different conformation (or be less ordered) in solution. 
a

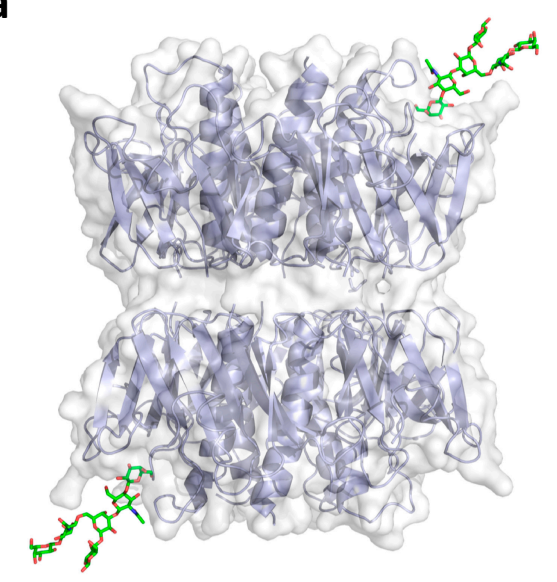

C

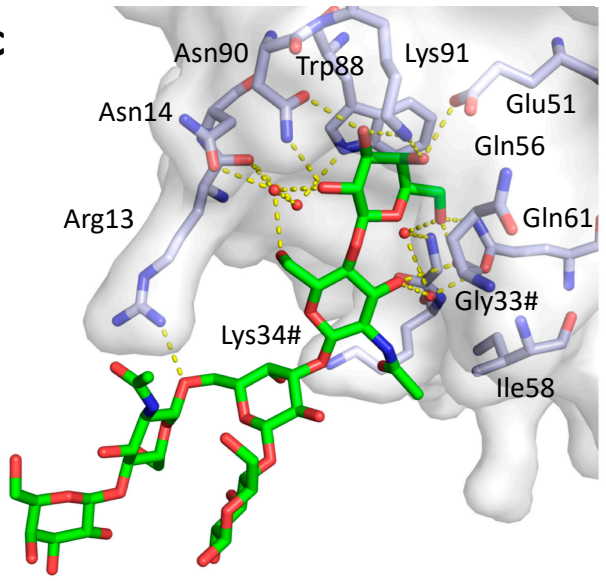

d

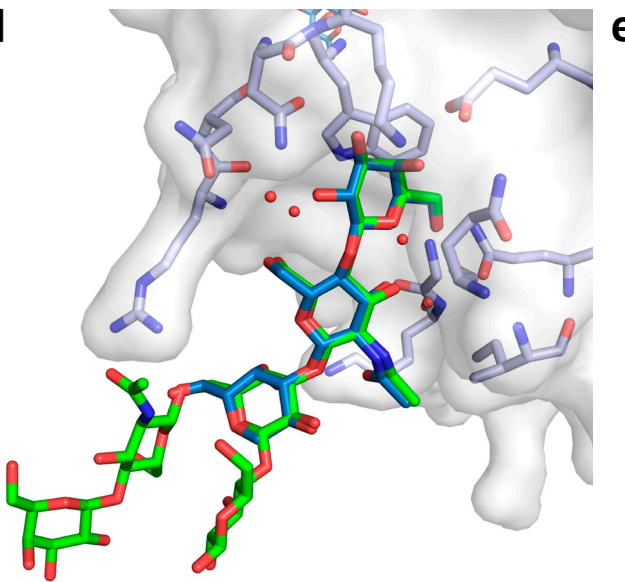

b
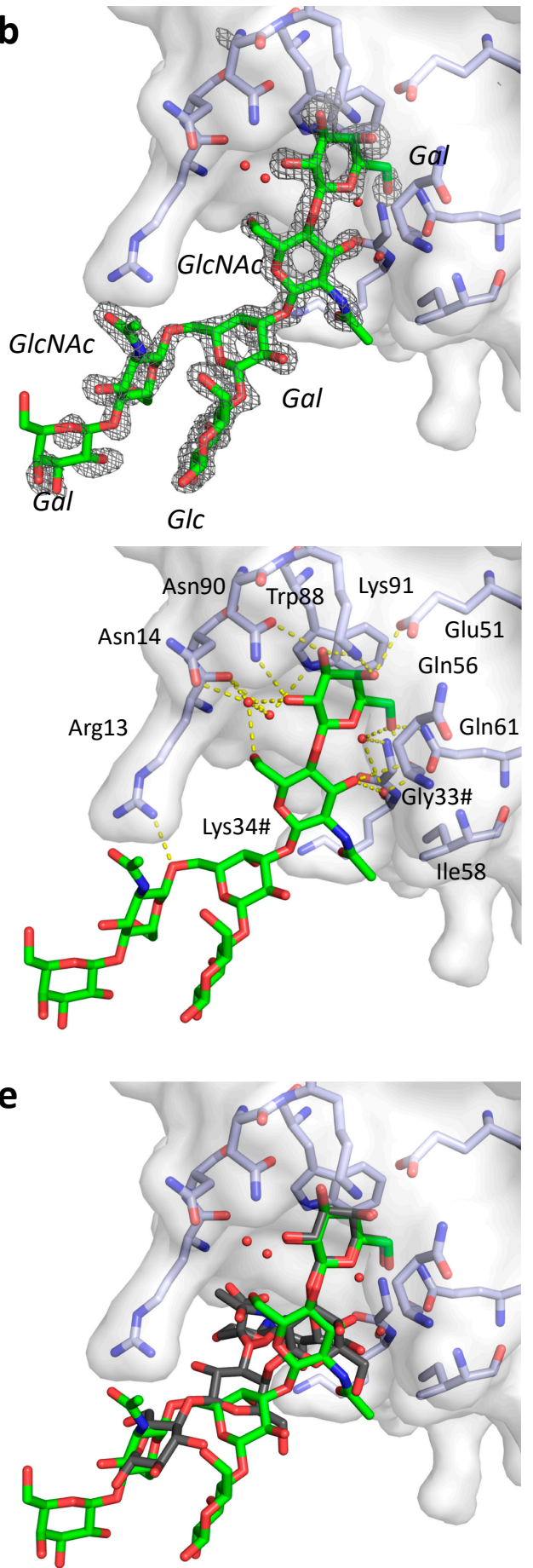

Figure 3. Structure of pLTB in complex with lacto- $N$-neohexaose (PDB ID: 6IAL, this work; LNnH shown in stick representation with green carbons). (a) Overview of the asymmetric unit, with two B-pentamers positioned "top-to-top" and two LNnH molecules bound. (b) Close-up view of the ligand binding site, with $\sigma_{\mathrm{A}}$-weighted $F_{\mathrm{O}}-F_{\mathrm{C}}$ electron density map shown in grey mesh contoured at $3.0 \sigma$, generated before placing the ligand. (c) Stereo-image of the binding site, with important residues labeled, H-bonding interactions shown as yellow dotted lines, and selected water molecules depicted as red spheres. Residues from the neighboring subunit are indicated by a hash (\#). (d) Close-up view of the LNnH binding site superimposed with LNnT (blue) from structure 2XRS [10]. (e) Close-up view of the LNnH binding site superimposed with GM1 pentasaccharide (grey) from structure 2XRQ [10]. 
Table 3. Data collection and refinement statistics

\begin{tabular}{cc}
\hline Protein & pLTB + LNnH \\
\hline PDB ID & $6 \mathrm{IAL}$ \\
Data collection & \\
Space group & $22_{1}$ \\
Cell dimensions & $77.1,65.6,96.3$ \\
a, b, c $(\AA)$ & 108.6 \\
$\beta\left(^{\circ}\right)$ & $68.7-1.45^{*}(1.47-1.45)^{* *}$ \\
Resolution $(\AA)$ & $160,263(7,848)$ \\
No. of unique reflections & $99.6(45.8)$ \\
CC $(1 / 2)(\%)$ & $0.13(1.15)$ \\
$R_{\text {merge }}$ & $6.4(1.3)$ \\
$(I) / \sigma(I)$ & $4.4(4.5)$ \\
Multiplicity & $99.6(99.0)$ \\
Completeness $(\%)$ & $17.5 / 20.1$ \\
Refinement & \\
$R_{\text {cryst }} / \mathrm{R}_{\text {free }}(\%)$ & 8622 \\
No. of atoms & $158 / 15$ \\
Protein & 644 \\
Ligand $/$ ion & \\
Water & 19.6 \\
Pverage $B$-factors $\left(\AA^{2}\right)$ & $23.2 / 19.7$ \\
Protein & 23.2 \\
Ligand /ion & 0.01 \\
Water & 1.7 \\
r.m.s.d. bonds $(\AA)$ & \\
r.m.s.d. angles $\left({ }^{\circ}\right)$ & \\
\hline
\end{tabular}

* Data collected on a single crystal. ${ }^{*}$ Values for the highest resolution shell are shown in parentheses.

Table 4. Protein-carbohydrate interactions to LNnH (PDB ID: 6IAL)

\begin{tabular}{|c|c|c|c|}
\hline Residue & Donor/acceptor & Distance (Å) Site 1 & Distance (Å) Site 2 \\
\hline Arg13 & NH1-O6 Galß34 (second Gal) & 2.9 & 3.2 \\
\hline \multirow[t]{2}{*}{ Asn14 } & OD1-O2 Galß3 via solvent & $3.0-\mathrm{H}_{2} \mathrm{O}-2.9$ & - \\
\hline & and O6 GlcNAc $\beta 3$ via solvent & $3.0-\mathrm{H}_{2} \mathrm{O}-2.8$ & - \\
\hline Gly33\# & N-O6 Gal $\beta 4$ via solvent & $2.8-\mathrm{H}_{2} \mathrm{O}-2.9$ & $2.9-\mathrm{H}_{2} \mathrm{O}-3.0$ \\
\hline Glu51 & OE2-O4 Gal $\beta 4$ & 2.7 & 2.7 \\
\hline \multirow[t]{2}{*}{ Gln56 } & O-O6 Gal $\beta 4$ & 2.7 & 2.6 \\
\hline & $\mathrm{O}-\mathrm{O} 3 \mathrm{GlcNAc} \beta 3$ & 2.8 & 2.9 \\
\hline Ile58 & GlcNAc $\beta 3$ & $3.6^{*}$ & $4.3^{*}$ \\
\hline \multirow[t]{2}{*}{ Gln61 } & NE2-O6 Gal $\beta 4$ & 3.0 & 3.0 \\
\hline & OD1-O3 GlcNAc $\beta 3$ via solvent & $2.8-\mathrm{H}_{2} \mathrm{O}-2.8$ & $2.9-\mathrm{H}_{2} \mathrm{O}-2.9$ \\
\hline \multirow[t]{2}{*}{ Asn90 } & ND2-O2 Gal $\beta 4$ & 2.9 & 2.9 \\
\hline & OD1-O3 Gal $\beta 4$ & 2.9 & 2.9 \\
\hline \multirow[t]{2}{*}{ Lys91 } & NZ-O3 Gal $\beta 4$ & 2.8 & 2.8 \\
\hline & NZ-O4 Gal $\beta 4$ & 2.9 & 2.8 \\
\hline
\end{tabular}




\section{Discussion}

We set out to explore the broader specificity of E. coli heat-labile enterotoxin (LT) compared to the cholera toxin (CT) with single-residue substitutions, using SPR spectroscopy. Unexpectedly, we recorded relatively large variation between analyte batches. Since sugars unlike proteins and nucleic acids do not contain any residues amenable for calibration using extinction coefficients, and the molecules are prohibitively expensive to obtain large amounts, we dealt with the variation by collecting as many data as possible per batch and including PLTB wt whenever possible as reference to enable comparison within batches of analytes.

Most of the single-site variants showed no or very small differences in affinity to LNnT compared to the parent toxins. The largest drop in activity was recorded upon mutation of Ile58 ( $>50 \mathrm{mM})$, a residue present in all enterotoxins included in this study. Almost as dramatic was the effect of mutating Asn94 to His ( $>40 \mathrm{mM}$ ), which dropped the affinity to levels as low as for CTB. Given that pLTB and hLTB feature an asparagine residue at this position, it is likely that this substitution critically determines the lower monovalent affinity of $\mathrm{CT}$ versus LT. In addition, we observed decreases in binding affinity for pLTB variants S95A and E7D $(15-20 \mathrm{mM})$, which is in a similar range compared to hLTB. Both of these residues are located between the primary and secondary toxin binding sites, with residue 95 closer to the primary binding site and residue 7 bordering the secondary binding site (Figure 1). A small reduction in binding affinity was also recorded for the $\mathrm{Y} 18 \mathrm{H}$ variant $(11 \mathrm{mM})$, while the other mutations showed no significant effects. Like Asn94, Tyr18 is located near the secondary toxin binding site, involved in the same H-bonding network as Asn94 (Figure 1c,d). The results may be explained by a change in the hydrogen-bonding network between the primary and secondary binding sites.

As notable as the effects of residues 94,95 , and 7 was the absence of significant effects for substitutions at positions 4 and 13. These two residues have received prime attention in earlier studies, using microtiter well assays $[10,17]$. It is worth noting that the SPR analysis performed here probed for monovalent binding, since the proteins were coupled to the SPR chips, whereas the microtiter well assays measured multivalent binding and avidity to immobilized glycolipids. The latter method gives a better view of the situation in vivo, however, both studies are needed to fully comprehend the underlying molecular interactions. Indications are that Ser/Thr4 and Arg13 are more important for multivalent binding than for monovalent binding. In the right context, Arg13 does not even seem be required for multivalent binding, as the CT-like toxin from Citrobacter freundii has been shown to bind even more strongly to LNnT-Cer than PLTB, despite exhibiting a histidine residue at position 13 [15]. Notably, this toxin features Glu7, Tyr18, Asn94, and Ser95-all residues identified as important in the current study. In this context, even Asn4 does not abrogate binding, in contrast to previous reports for the LTB/CTB chimera LCTBK compared to LCTBH [17].

Whereas the largest differences in binding affinity are between LTB and CTB, there are also small, but noticeable differences between PLTB and hLTB, accounting approximately for a factor two in monovalent binding affinity (Table 1). The only sequence differences between these two toxins concern residues $4,13,46$, and 102, none of which showed a significant effect in our investigation. This strongly suggests that the substitutions have synergistic effects, as previously shown for regions 1-25 and 94-95 [14]. While we cannot be certain about the effects, we noticed that both residues 4 and 102 lie at the B-subunit interface and may affect binding affinity in concert, either by conformational pre-alignment or by pre-stabilizing the structure of the toxin. In this context it is interesting to note that pLTB crystallizes more easily compared to hLTB (this is even true for pLTB R13H [29]), which may rely on a similar effect, and points to pre-stabilization as a possible factor, reducing the entropic barrier to binding.

The original motivation for dissecting the broader binding specificity of LT versus CT was vaccine design [30]. The CT B-pentamer is a component of the major cholera vaccine [31], and the binding of CTB or LTB to cells has been shown to enhance immunogenicity [32,33]. It is conceivable that the inclusion of LTB or CTB/LTB hybrids with broader binding specificities could make vaccines 
more effective to combat several types of enterotoxigenic infections. This strategy is currently probed in clinical trials with the second generation oral ETEC vaccine [34,35], which includes a CTB/LTB chimera as well as a double-mutated LT holotoxin [36]. The work presented here may further aid the development of improved cholera and ETEC vaccines.

\section{Materials and Methods}

\subsection{Generation of Single-Site Variants}

Nucleotide sequences of pLTB (Uniprot accession number P32890) and hLTB (Uniprot accession number P0CK94) were ordered from the GeneArt gene synthesis service (Thermo Fisher Scientific, Waltham, MA, USA), codon-optimized for expression in E. coli. The genes were subcloned into vector pET21b(+) (Novagen, Merck, Darmstadt, Germany). Single-site mutations were introduced using the Quikchange kit (Agilent Technologies, Santa Clara, CA, USA) or the NEB Q5 site-directed mutagenesis kit (New England Biolabs, Ipswich, MA, USA). The resulting plasmids were verified by DNA sequencing, and the purified proteins were later checked for proper folding using circular dichroism. The protein sequences for the proteins used in this study were as follows: pLTB: APQTITELCS EYRNTQIYTI NDKILSYTES MAGKREMVII TFKSGETFQV EVPGSQHIDS QKKAIERMKD TLRITYLTET KIDKLCVWNN KTPNSIAAIS MKN; hLTB: APQSITELCS EYHNTQIYTI NDKILSYTES MAGKREMVII TFKSGATFQV EVPGSQHIDS QKKAIERMKD TLRITYLTET KIDKLCVWNN KTPNSIAAIS MEN; and CTB (El Tor biotype): TPQNITDLCA EYHNTQIYTL NDKIFSYTES LAGKREMAII TFKNGAIFQV EVPGSQHIDS QKKAIERMKD TLRIAYLTEA KVEKLCVWNN KTPHAIAAIS MAN.

\subsection{Production and Purification of Protein}

pLTB variants were transformed into E. coli BL21 (DE3) cells for expression. Note that this expression system differs from the one used in previous studies from our group. The cells were grown in LB medium supplemented with $0.1 \mathrm{mg} / \mathrm{mL}$ ampicillin at $37^{\circ} \mathrm{C}$ until an $\mathrm{OD}_{600 \mathrm{~nm}}$ of 0.5 was reached. The temperature was lowered to $25^{\circ} \mathrm{C}$, the cells were induced with $0.5 \mathrm{mM}$ IPTG, and incubated for 16-20 h. Cells were harvested by centrifugation at $6900 \times g$, and the pellet re-suspended in periplasmic extraction buffer $\left(5 \mathrm{mM} \mathrm{MgCl}_{2}, 0.1 \mathrm{mg} / \mathrm{mL}\right.$ lysozyme, protease inhibitor cocktail (Roche, Basel, Switzerland). The periplasmic fraction was separated from the cell debris by centrifugation, and dialyzed against PBS, before being applied to a D-Gal-sepharose gravity column (Thermo Fisher Scientific, Waltham, MA, USA). The bound protein was eluted with $300 \mathrm{mM}$ D-Gal in PBS, and concentrated to $2-5 \mathrm{mg} / \mathrm{mL}$. The protein was then applied to a Superdex 75 size-exclusion chromatography column (GE Healthcare, Chicago, IL, USA), where the buffer was exchanged to $20 \mathrm{mM}$ Tris- $\mathrm{HCl} \mathrm{pH} 7.5,100 \mathrm{mM} \mathrm{NaCl}$. This protocol resulted in a yield of approximately $0.4 \mathrm{mg}$ of purified protein per liter of culture. The proteins were kept at $4{ }^{\circ} \mathrm{C}$ for short term storage, and at $-80^{\circ} \mathrm{C}$ for long term storage.

hLTB wt and CTB were produced in Vibrio sp. 60, which secretes proteins into the growth medium. Cells were grown in $\mathrm{LB}$ medium supplemented with $15 \mathrm{~g} / \mathrm{L} \mathrm{NaCl}$ and $0.1 \mathrm{mg} / \mathrm{mL}$ ampicillin at $30^{\circ} \mathrm{C}$ until an $\mathrm{OD}_{600 \mathrm{~nm}}$ of 0.2 was reached. After induction with $0.5 \mathrm{mM}$ IPTG, expression proceeded for $16-24 \mathrm{~h}$ until the cells were separated from the medium by centrifugation at $40,000 \times g$. The cleared medium was applied to a D-Gal-sepharose gravity column, and eluted with $300 \mathrm{mM}$ D-Gal in PBS. The protein was subsequently concentrated to $2-5 \mathrm{mg} / \mathrm{mL}$ and applied to a Superdex 75 size-exclusion column, where the buffer was exchanged to $20 \mathrm{mM}$ Tris- $\mathrm{HCl} \mathrm{pH} 7.5,100 \mathrm{mM} \mathrm{NaCl}$. This protocol resulted in a yield of approximately $6 \mathrm{mg}$ of purified protein per liter of culture. The proteins were kept at $4{ }^{\circ} \mathrm{C}$ for short term storage, and at $-80{ }^{\circ} \mathrm{C}$ for long term storage. 


\subsection{Analysis by Surface Plasmon Resonance}

Prior to SPR experiments, the protein was dialyzed against PBS. The experiments were performed on a Biacore T100 biosensor system (GE Healthcare, Chicago, IL, USA) at the Infrastructural Center for Analysis of Molecular Interactions, University of Ljubljana, Slovenia. All experiments were carried out at $25^{\circ} \mathrm{C}$ in HBS-EP running buffer (10 mM Hepes pH 7.4, $150 \mathrm{mM} \mathrm{NaCl}, 3 \mathrm{mM}$ EDTA, $0.005 \%$ $(v / v)$ surfactant P20), and the analytes lacto- $N$-neotetraose (LNnT; Elicityl-oligotech, Crolles, France, product code GLY021) or branched lacto- $N$-neohexaose (LNnH; Dextra Laboratories LtD, Reading, UK, product code L605) were solubilized in the same buffer. LnNT was ordered and shipped from the supplier at four different time points (batches 1 to 4 ). The analytes were weighed out using a high precision scale, but inaccuracies may have been introduced at this stage due to the difficulties in measuring a few milligrams of material. This or differences in additives like salts or impurities are most likely the cause of the small discrepancies between batches. The proteins were diluted in $10 \mathrm{mM}$ sodium acetate $\mathrm{pH} 5.5$ and immobilized by amine coupling to a CM5 sensor chip (GE Healthcare, Chicago, IL, USA) to a response of 2500-6000 RU.

The experiments with LNnT were done in four rounds: the first round included pLTB R13H and hLTB H13R (without the wild types since the values were thought to be known from the preliminary experiments). LNnT was injected over the surfaces with a flow rate of $5 \mu \mathrm{L} / \mathrm{min}, 30 \mathrm{~s}$ contact time at increasing concentrations of the carbohydrate analyte $(0.156 \mathrm{mM}$ to $40 \mathrm{mM})$, with one injection per concentration, and repeated two times. The second round included pLTB wt, E7D, I58A, and N94H, with a flow rate of $20 \mu \mathrm{L} / \mathrm{min}$ for $60 \mathrm{~s}$ (followed by a $60 \mathrm{~s}$ dissociation phase and allowing $60 \mathrm{~s}$ of stabilization prior to the next injection), and repeated three times. The third round included variants pLTB wt, T4N, T4S, Y18H, E46A, S95A, K102E, and CTB, with a similar protocol, with an increasing analyte concentration up to $30 \mathrm{mM}$. Due to a slight increase in baseline, $3 \mathrm{mM} \mathrm{NaOH}$ was used for regeneration of the chip between each injection. In the fourth round we repeated pLTB wt and T4N, using the same protocol as previously. The experiments with $\mathrm{LNnH}$ were performed equivalently to those with LNnT with a few exceptions. The experiments were done once with two runs of analyte, due to the high cost of the analyte. $\mathrm{LNnH}$ was injected over the surfaces at increasing concentrations of analyte $(0.0098 \mathrm{mM}$ to $10 \mathrm{mM})$, with one injection per concentration.

The SPR experiments with analyte GM1 pentasaccharide (GM1a; Elicityl-oligotech, Crolles, France, product code GLY096) were performed as described in [26]. In brief, the analyte was injected at increasing concentrations (up to $200 \mathrm{nM}$ ) over the CM5 sensor chip to which the protein was immobilized. All experiments were performed in duplicate. The dissociation constants for LNnT and LNnH were calculated by using a steady-state affinity model, while the GM1a data was fitted to a Langmuir 1:1 interaction model, using the Biacore T100 evaluation software.

\subsection{Crystallographic Analysis}

pLTB $(5.6 \mathrm{mg} / \mathrm{mL})$ and $\mathrm{LNnH}$ were mixed at a molar ratio of 1:10 (B-subunit:ligand) $2 \mathrm{~h}$ prior to crystallization. Sitting drop vapor diffusion experiments $(300 \mathrm{~nL}$ protein solution $+300 \mathrm{~nL}$ crystallization buffer) were set up using an Oryx4 crystallization robot (Douglas Instruments, East Garston, UK). pLTB in complex with LNnH crystallized at $20^{\circ} \mathrm{C}$ in the PACT premier screen condition A9 (0.1 M sodium acetate $\mathrm{pH} 5.0,20 \% w / v$ PEG 6000, $0.2 \mathrm{M} \mathrm{LiCl})$. Diffraction-quality crystals were flash-cooled in a nitrogen cryo-stream.

Synchrotron data collection was performed at beamline ID23-2, ESRF, Grenoble, France (100 K, $0.8729 \AA$ A). Data were processed with xia2/DIALS and AIMLESS from the CCP4 software suite [37,38], and cut to a resolution of $1.65 \AA$ by assessing statistical parameters including the $C C_{1 / 2}$ value. The structure was solved by molecular replacement with the program Phaser [39] from the CCP4 software suite using PDB entry 1DJR [40] as the search model. To reduce model bias, five cycles of refinement including two cycles with simulated annealing were carried out with the Phenix software suite [41]. The structure was refined by alternating manual building with Coot and automatic refinement with REFMAC5 [42,43]. Refinement steps involved local non-crystallographic symmetry 
(NCS) restraints and TLS model parameterization (REFMAC5, automatic, five cycles). PDB_REDO was used to evaluate and automatically optimize the model [44]. Water molecules were first automatically placed in Coot and then manually inspected. $\mathrm{LNnH}$ was included last and built using MAKE LIGAND (AceDRG [45]) from the CCP4 software suite and an isomeric SMILES string (from PubChem Sketcher). The disulphide bond between Cys9 and Cys96 showed signs of being partially reduced in all subunits, and was modeled with an alternative conformation by changing the SSBOND entries in the PDB file to LINKR entries. Data initially processed with DIALS (without scaling by xia2) were directly scaled with AIMLESS leading to better data statistics. Data were cut to a resolution of $1.45 \AA$ by assessing statistical parameters including the $C_{1 / 2}$ value, and used for final refinement steps. The final model was analysed using the Analyse geometry task of the CCP4 software suite. The atomic coordinates and structure factors have been deposited in the PDB under entry 6IAL. Figures were generated using PyMol (Schrödinger LLC, New York City, NY, USA).

\section{Conclusions}

Using SPR spectroscopy, we probed the effect of a number of single-site substitutions between pLTB, hLTB, and CTB. In addition to Ile 58 , which is conserved in all toxin variants, the largest effect was found upon substituting Asn94, followed by Ser95 and Glu7, and Tyr18. Intriguingly, these residues lie on two paths connecting the primary and secondary toxin binding sites, which have previously been implicated in allosteric cross-talk $[10,26,27]$. This cross-talk may not only be important for the communication between the sites, but also directly affect binding affinity and specificity, with important implications for the biological mechanism of the toxins.

Supplementary Materials: Supplementary materials can be found at http:/ /www.mdpi.com/1422-0067/20/3/ $703 /$ s1.

Author Contributions: Conceptualization, U.K.; Investigation-production and purification of LTB variants, J.E.H. and J.B.H.; Investigation-SPR analysis, J.E.H., J.B.H., V.H., and G.B.; Investigation-X-ray diffraction, J.B.H.; Validation-SPR analysis, V.H. and G.A.; Validation-crystal structure, J.E.H., J.B.H., and U.K.; Resources, G.A. and U.K.; Data curation, J.B.H., V.H., G.A., and U.K.; Supervision, G.A. and U.K.; Writing-first complete draft, J.E.H. and U.K.; Writing-review and editing, J.B.H. and V.H.; Writing-minor comments and approval, G.B. and G.A.; Visualization, J.E.H. and J.B.H.; Project administration, U.K.; Funding acquisition, U.K. and G.A.

Funding: This research was funded by the Norwegian Research Council, grant numbers 171631, 183613 (FUGE-GlycoNor) and 247730, and by the University of Oslo (financial support to J.E.H. and J.B.H.).

Acknowledgments: Przemysław Szymański contributed importantly to this work as Erasmus Master's student. Unfortunately, we were unable to contact him for final approval of the manuscript. We are further grateful to Per Eugen Kristiansen for circular dichroism support, and to Rune Johansen Forstrøm and Magnar Bjørås for support regarding preliminary SPR experiments at the Center for Molecular and Behavioral Neuroscience, at the Oslo University hospital. Finally, we thank the staff of the ESRF for assistance and support using beamline ID23-2. Protein crystallization and preliminary X-ray diffraction experiments were carried out at the UiO X-ray core facilities.

Conflicts of Interest: The authors declare no conflict of interest.

\section{Abbreviations}

\begin{tabular}{|c|c|}
\hline MDPI & Multidisciplinary Digital Publishing Institute \\
\hline $\mathrm{CD}$ & circular dichroism \\
\hline Cer & ceramide \\
\hline $\mathrm{CT}$ & cholera toxin \\
\hline СТВ & cholera toxin, pentamer of B-subunits \\
\hline GD2 & disialoganglioside GalNAc $\beta 4[\mathrm{NeuAc} \alpha 8 \mathrm{NeuAc} \alpha 3] \mathrm{Gal} \beta 4 \mathrm{Glc} \beta \mathrm{Cer}$ \\
\hline GlcNAc & $2^{\prime}-N$-acetyl glucosamine \\
\hline GM1 & monosialoganglioside Gal $\beta 3 \mathrm{GalNAc} \beta 4[\mathrm{NeuAc} \alpha 3] \mathrm{Gal} \beta 4 \mathrm{Glc} \beta \mathrm{Cer}$ \\
\hline hLT & Escherichia coli heat-labile enterotoxin from human isolates \\
\hline hLTB & E. coli heat-labile enterotoxin from human isolates, pentamer of B-subunits \\
\hline $\mathrm{LNnH}$ & lacto- $N$-neohexaose Gal $\beta 4 \mathrm{GlcNAc} \beta 6[\mathrm{Gal} \beta 4 \mathrm{GlcNAc} \beta 3] \mathrm{Gal} \beta 4 \mathrm{Glc}$ \\
\hline
\end{tabular}




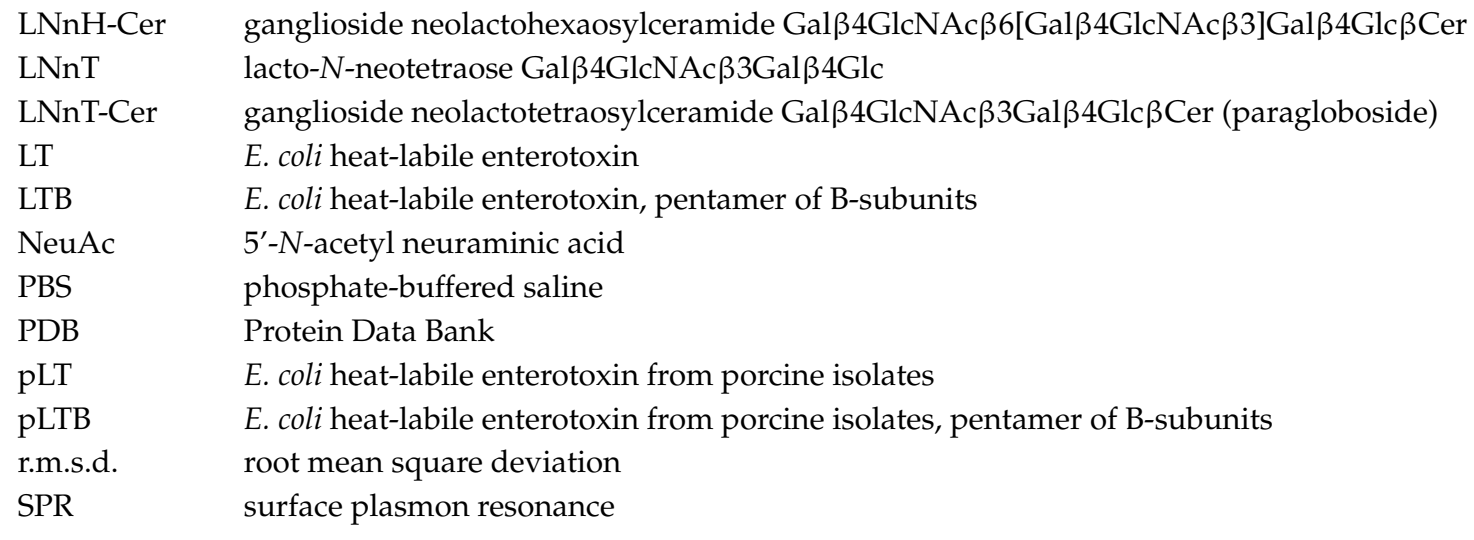

\section{References}

1. Khalil, I.A.; Troeger, C.; Blacker, B.F.; Rao, P.C.; Brown, A.; Atherly, D.E.; Brewer, T.G.; Engmann, C.M.; Houpt, E.R.; Kang, G.; et al. Morbidity and mortality due to shigella and enterotoxigenic Escherichia coli diarrhoea: The Global Burden of Disease Study 1990-2016. Lancet Infect. Dis. 2018, 11, 1229-1240. [CrossRef]

2. Guerrant, R.L.; DeBoer, M.D.; Moore, S.R.; Scharf, R.J.; Lima, A.A.M. The impoverished gut-a triple burden of diarrhoea, stunting and chronic disease. Nat. Rev. Gastroenterol. Hepatol. 2013, 10, 220-229. [CrossRef] [PubMed]

3. Halvorson, H.A.; Schlett, C.D.; Riddle, M.S. Postinfectious irritable bowel syndrome-A meta-analysis. Am. J. Gastroenterol. 2006, 101, 1894-1899. [CrossRef] [PubMed]

4. Merritt, E.A.; Hol, W.G.J. AB 5 toxins. Curr. Opin. Struct. Biol. 1995, 5, 165-171. [CrossRef]

5. Heggelund, J.E.; Bjørnestad, V.A.; Krengel, U. Vibrio cholerae and Escherichia coli heat-labile enterotoxins and beyond. In The Comprehensive Sourcebook of Bacterial Protein Toxins; Alouf, J.E., Ladant, D., Popoff, M.R., Eds.; Elsevier: Amsterdam, The Netherlands, 2015; pp. 195-229. [CrossRef]

6. Kuziemko, G.M.; Stroh, M.; Stevens, R.C. Cholera toxin binding affinity and specificity for gangliosides determined by surface plasmon resonance. Biochemistry 1996, 35, 6375-6384. [CrossRef] [PubMed]

7. Turnbull, W.B.; Precious, B.L.; Homans, S.W. Dissecting the cholera toxin-ganglioside GM1 interaction by isothermal titration calorimetry. J. Am. Chem. Soc. 2004, 126, 1047-1054. [CrossRef] [PubMed]

8. Lauer, S.; Goldstein, B.; Nolan, R.L.; Nolan, J.P. Analysis of cholera toxin-ganglioside interactions by flow cytometry. Biochemistry 2002, 41, 1742-1751. [CrossRef] [PubMed]

9. Merritt, E.A.; Kuhn, P.; Sarfaty, S.; Erbe, J.L.; Holmes, R.K.; Hol, W.G.J. The 1.25 Å resolution refinement of the cholera toxin B-pentamer: Evidence of peptide backbone strain at the receptor-binding site. J. Mol. Biol. 1998, 282, 1043-1059. [CrossRef]

10. Holmner, Å.; Mackenzie, A.; Ökvist, M.; Jansson, L.; Lebens, M.; Teneberg, S.; Krengel, U. Crystal structures exploring the origins of the broader specificity of Escherichia coli heat-labile enterotoxin compared to cholera toxin. J. Mol. Biol. 2011, 406, 387-402. [CrossRef]

11. Merritt, E.A.; Sarfaty, S.; Jobling, M.G.; Chang, T.; Holmes, R.K.; Hirst, T.R.; Hol, W.G.J. Structural studies of receptor binding by cholera toxin mutants. Protein Sci. 1997, 6, 1516-1528. [CrossRef]

12. Fukuta, S.; Magnani, J.L.; Twiddy, E.M.; Holmes, R.K.; Ginsburg, V. Comparison of the carbohydrate-binding specificities of cholera toxin and Escherichia coli heat-labile enterotoxins LTh-I, LT-IIa, and LT-IIb. Infect. Immunity 1988, 56, 1748-1753.

13. Ångström, J.; Teneberg, S.; Karlsson, K.A. Delineation and comparison of ganglioside-binding epitopes for the toxins of Vibrio cholerae, Escherichia coli, and Clostridium tetani: Evidence for overlapping epitopes. Proc. Natl. Acad. Sci. USA 1994, 91, 11859-11863. [CrossRef] [PubMed]

14. Bäckström, M.; Shahabi, V.; Johansson, S.; Teneberg, S.; Kjellberg, A.; Miller-Podraza, H.; Holmgren, J.; Lebens, M. Structural basis for differential receptor binding of cholera and Escherichia coli heat-labile toxins: Influence of heterologous amino acid substitutions in the cholera B-subunit. Mol. Microbiol. 1997, 24, 489-497. [CrossRef] [PubMed] 
15. Jansson, L.; Ångström, J.; Lebens, M.; Imberty, A.; Varrot, A.; Teneberg, S. Carbohydrate binding specificities and crystal structure of the cholera toxin-like B-subunit from Citrobacter freundii. Biochimie 2010, 92, 482-490. [CrossRef] [PubMed]

16. Teneberg, S.; Berntsson, A.; Ångström, J. Common architecture of the primary galactose binding sites of Erythrina corallodendron lectin and heat-labile enterotoxin from Escherichia coli in relation to the binding of branched neolactohexaosylceramide. J. Biochem. 2000, 128, 481-491. [CrossRef]

17. Ångström, J.; Bäckström, M.; Berntsson, A.; Karlsson, N.; Holmgren, J.; Karlsson, K.-A.; Lebens, M.; Teneberg, S. Novel carbohydrate binding site recognizing blood group A and B determinants in a hybrid of cholera toxin and Escherichia coli heat-labile enterotoxin B-subunits. J. Biol. Chem. 2000, 275, 3231-3238. [CrossRef]

18. Holmner, Å.; Lebens, M.; Teneberg, S.; Ångström, J.; Ökvist, M.; Krengel, U. Novel binding site identified in a hybrid between cholera toxin and heat-labile enterotoxin: $1.9 \AA$ crystal structure reveals the details. Structure 2004, 12, 1655-1667, Erratum in: Structure 2007, 15, 253. [CrossRef]

19. Holmner, Å.; Askarieh, G.; Ökvist, M.; Krengel, U. Blood group antigen recognition by Escherichia coli heat-labile enterotoxin. J. Mol. Biol. 2007, 371, 754-764. [CrossRef]

20. Heggelund, J.E.; Burschowsky, D.; Bjørnestad, V.A.; Hodnik, V.; Anderluh, G.; Krengel, U. High-resolution crystal structures elucidate the molecular basis of cholera blood group dependence. PLoS Pathog. 2016, 12, e1005567. [CrossRef]

21. Heggelund, J.E.; Haugen, E.; Lygren, B.; Mackenzie, A.; Holmner, Å.; Vasile, F.; Reina, J.J.; Bernardi, A.; Krengel, U. Both El Tor and classical cholera toxin bind blood group determinants. Biochem. Biophys. Res. Commun. 2012, 418, 731-735. [CrossRef]

22. Mandal, P.K.; Branson, T.R.; Hayes, E.D.; Ross, J.F.; Gavín, J.A.; Daranas, A.H.; Turnbull, W.B. Towards a structural basis for the relationship between blood group and the severity of El Tor cholera. Angew. Chem. Int. Ed. Engl. 2012, 51, 5143-5146. [CrossRef]

23. Vasile, F.; Reina, J.J.; Potenza, D.; Heggelund, J.E.; Mackenzie, A.; Krengel, U.; Bernardi, A. Comprehensive analysis of blood group antigen binding to classical and El Tor cholera toxin B-pentamers by NMR. Glycobiology 2014, 24, 766-778. [CrossRef] [PubMed]

24. Holmner-Rocklöv, Å. Molecular recognition of carbohydrates-Structural and functional Characterisation of bacterial toxins and fungal lectins. Ph.D. Thesis, Chalmers University of Technology, Gothenburg, Sweden, 2005.

25. Jansson, L.; Ångström, J.; Lebens, M.; Teneberg, S. No direct binding of the heat-labile enterotoxin of Escherichia coli to E. coli lipopolysaccharides. Glycoconj. J. 2010, 27, 171-179. [CrossRef]

26. Heim, J.B.; Hodnik, V.; Heggelund, J.E.; Anderluh, G.; Krengel, U. Crystal structures reveal that Lewis-x and fucose bind to secondary cholera toxin binding site-in contrast to fucosyl-GM1. bioRxiv 2018, 2018, 431130. [CrossRef]

27. Hatlem, D.; Heggelund, J.E.; Burschowsky, D.; Krengel, U.; Kristiansen, P.E. ${ }^{1} \mathrm{H},{ }^{13} \mathrm{C},{ }^{15} \mathrm{~N}$ backbone assignment of the human heat-labile enterotoxin B-pentamer and chemical shift mapping of neolactotetraose binding. Biomol. NMR Assign. 2017, 11, 99-104. [CrossRef]

28. Karlsson, K.-A.; Teneberg, S.; Ångström, J.; Kjellberg, A.; Hirst, T.R.; Bergström, J.; Miller-Podraza, H. Unexpected carbohydrate cross-binding by Escherichia coli heat-labile enterotoxin. Recognition of human and rabbit target cell glycoconjugates in comparison with cholera toxin. Bioorg. Med. Chem. 1996, 4, 1919-1928. [CrossRef]

29. Heggelund, J.E.; Mackenzie, A.; Martinsen, T.; Heim, J.B.; Cheshev, P.; Bernardi, A.; Krengel, U. Towards new cholera prophylactics and treatment: Crystal structures of bacterial enterotoxins in complex with GM1 mimics. Sci. Rep. 2017, 7, 2326. [CrossRef]

30. Lebens, M.; Shahabi, V.; Bäckström, M.; Houze, T.; Lindblad, N.; Holmgren, J. Synthesis of hybrid molecules between heat-labile enterotoxin and cholera toxin B subunits: Potential for use in a broad-spectrum vaccine. Infect. Immunity 1996, 64, 2144-2150.

31. Harris, J.B. Cholera: Immunity and prospects in vaccine development. J. Infect. Dis. 2018, 218, S141-S146. [CrossRef]

32. Francis, M.L.; Ryan, J.; Jobling, M.G.; Holmes, R.K.; Moss, J.; Mond, J.J. Cyclic AMP-independent effects of cholera toxin on B cell activation. II. Binding of ganglioside GM1 induces B cell activation. J. Immunol. 1992, $148,1999-2005$. 
33. Nashar, T.O.; Webb, H.M.; Eaglestone, S.; Williams, N.A.; Hirst, T.R. Potent immunogenicity of the B subunits of Escherichia coli heat-labile enterotoxin: Receptor binding is essential and induces differential modulation of lymphocyte subsets. Proc. Natl. Acad. Sci. USA 1996, 93, 226-230. [CrossRef] [PubMed]

34. Holmgren, J.; Bourgeois, L.; Carlin, N.; Clements, J.; Gustafsson, B.; Lundgren, A.; Nygren, E.; Tobias, J.; Walker, R.; Svennerholm, A.-M. Development and preclinical evaluation of safety and immunogenicity of an oral ETEC vaccine containing inactivated E. coli bacteria overexpressing colonization factors CFA/I, CS3, CS5 and CS6 combined with a hybrid LT/CT B subunit antigen, administered alone and together with dmLT adjuvant. Vaccine 2013, 31, 2457-2464. [CrossRef] [PubMed]

35. Akhtar, M.; Chowdhury, M.I.; Bhuiyan, T.R.; Kaim, J.; Ahmed, T.; Rafique, T.A.; Khan, A.; Rahman, S.I.A.; Khanam, F.; Begum, Y.A.; et al. Evaluation of the safety and immunogenicity of the oral inactivated multivalent enterotoxigenic Escherichia coli vaccine ETVAX in Bangladeshi adults in a double-blind, randomized, placebo-controlled Phase I trial using electrochemiluminescence and ELISA assays for immunogenicity analyses. Vaccine 2018. [CrossRef]

36. Norton, E.B.; Lawson, L.B.; Freytag, L.C.; Clements, J.D. Characterization of a mutant Escherichia coli heat-labile toxin, LT(R192G/L211A), as a safe and effective oral adjuvant. Clin. Vaccine Immunol. 2011, 18, 546-551. [CrossRef] [PubMed]

37. Winn, M.D.; Ballard, C.C.; Cowtan, K.D.; Dodson, E.J.; Emsley, P.; Evans, P.R.; Keegan, R.M.; Krissinel, E.B.; Leslie, A.G.; McCoy, A.; et al. Overview of the CCP4 suite and current developments. Acta Crystallogr. D Biol. Crystallogr. 2011, 67, 235-242. [CrossRef] [PubMed]

38. Potterton, L.; Agirre, J.; Ballard, C.; Cowtan, K.; Dodson, E.; Evans, P.R.; Jenkins, H.T.; Keegan, R.; Krissinel, E.; Stevenson, K.; et al. CCP4i2: The new graphical user interface to the CCP4 program suite. Acta Crystallogr. D Struct. Biol. 2018, 74, 68-84. [CrossRef] [PubMed]

39. McCoy, A.J.; Grosse-Kunstleve, R.W.; Adams, P.D.; Winn, M.D.; Storoni, L.C.; Read, R.J. Phaser crystallographic software. J. Appl. Crystallogr. 2007, 40, 658-674. [CrossRef]

40. Minke, W.E.; Pickens, J.C.; Merritt, E.A.; Fan, E.; Verlinde, C.L.M.J.; Hol, W.G.J. Structure of $m$-carboxyphenyl- $\alpha$-D-galactopyranoside complexed to heat-labile enterotoxin at $1.3 \AA$ resolution: Surprising variations in ligand-binding modes. Acta Crystallogr. D Biol. Crystallogr. 2000, 56, 795-804. [CrossRef]

41. Adams, P.D.; Afonine, P.V.; Bunkóczi, G.; Chen, V.B.; Echols, N.; Headd, J.J.; Hung, L.-W.; Jain, S.; Kapral, G.J.; Grosse-Kunstleve, R.W.; et al. The Phenix software for automated determination of macromolecular structures. Methods 2011, 55, 94-106. [CrossRef]

42. Emsley, P.; Lohkamp, B.; Scott, W.G.; Cowtan, K. Features and development of Coot. Acta Crystallogr. D Biol. Crystallogr. 2010, 66, 486-501. [CrossRef]

43. Murshudov, G.N.; Skubák, P.; Lebedev, A.A.; Pannu, N.S.; Steiner, R.A.; Nicholls, R.A.; Winn, M.D.; Long, F.; Vagin, A.A. REFMAC5 for the refinement of macromolecular crystal structures. Acta Crystallogr. D Biol. Crystallogr. 2011, 67, 355-367. [CrossRef] [PubMed]

44. Joosten, R.P.; Long, F.; Murshudov, G.N.; Perrakis, A. The PDB_REDO server for macromolecular structure model optimization. IUCrJ 2014, 1, 213-220. [CrossRef] [PubMed]

45. Long, F.; Nicholls, R.A.; Emsley, P.; Gražulis, S.; Merkys, A.; Vaitkus, A.; Murshudov, G.N. AceDRG: A stereochemical description generator for ligands. Acta Crystallogr. D Struct. Biol. 2017, 73, 112-122. [CrossRef] [PubMed]

(C) 2019 by the authors. Licensee MDPI, Basel, Switzerland. This article is an open access article distributed under the terms and conditions of the Creative Commons Attribution (CC BY) license (http://creativecommons.org/licenses/by/4.0/). 